\title{
Does Age Make a Difference? Age as Moderator in the Association Between Time Perspective and Happiness
}

\author{
Marianne Simons ${ }^{1} \cdot$ Sanne Peeters $^{1,2} \cdot$ Mayke Janssens $^{1,2}$. \\ Johan Lataster $^{1,2} \cdot$ Nele Jacobs ${ }^{1,2}$
}

Published online: 6 October 2016

(C) The Author(s) 2016. This article is published with open access at Springerlink.com

\begin{abstract}
A balanced time perspective can help retaining or improving happiness. Research shows shifts in time perspective while ageing. In order to reach a better understanding of the value of time perspective in different age groups, results are reported of a survey $(n=525)$, which examines the moderating role of age in the association between time perspective and happiness. Time perspective was measured by the Zimbardo Time Perspective Inventory (ZTPI) (Zimbardo and Boyd in J Personal Soc Psychol 77:1271-1288, 1999) and to measure happiness, the Subjective Happiness Scale of Lyubomirsky and Lepper (Soc Indic Res 46:137-155, 1999) was used. Regression analysis shows that time perspective is indeed associated with happiness and that, although the assumed shifts in time perspective over time were not found, age does act as a moderator of this association. With ageing, the negative association between a past-negative time perspective and happiness weakens. These results add to our understanding of the theoretical concept of time perspective and shed new light on the value of a balanced time perspective for someone's wellbeing. Theoretical and practical implications of these findings are discussed.
\end{abstract}

Keywords Time perspective $\cdot$ Happiness $\cdot$ Well-being $\cdot$ Age $\cdot$ Ageing

\section{Introduction}

The present study aims to enhance the general understanding of the association between time perspective and happiness from a lifespan perspective, by examining the moderating role of age on this association. Research literature on time perspective does not yet contain

Marianne Simons

mariannesimons73@gmail.com

1 Faculty of Psychology and Educational Sciences, Open University of the Netherlands, Heerlen, The Netherlands

2 Department of Psychiatry and Neuropsychology, School for Mental Health and Neuroscience, Maastricht University, Maastricht, The Netherlands 
many studies that focus on this moderating role of age. We argue that age can affect time perspective and consequently its association with happiness.

In their theory of time perspective Zimbardo and Boyd (1999) described time perspective as a predominantly unconscious process of assigning personal and social experiences to time frames, that help individuals organize and value these events. They distinguished six different perspectives from which this process can be planned. The pastnegative time perspective (PN) represents a negative and pessimistic attitude towards the past; the past-positive time perspective (PP) is characterised by a positive and sentimental view on the past; the present-hedonistic time perspective (PH) concerns a hedonistic, pleasure-focused and risk-taking attitude; the present-fatalistic time perspective (PF) shows a fatalistic, helpless and hopeless view on the present and future; and the future time perspective (F) allows a focus on the future with concrete plans and goals. This fifth perspective usually includes the denial of short-term pleasures and the postponement of rewards as well. The sixth and last perspective is the transcendental-future time perspective (TF) that goes beyond earthly life and focuses on spiritual concepts.

Research shows that time perspective is associated with different aspects of well-being, including perceived happiness (i.e. Boniwell et al. 2010; Hicks et al. 2012; Zimbardo et al. 1997). Negative relations were found between past-negative and present-fatalistic time perspective and aspects of well-being (Crockett et al. 2009), whereas the past-negative perspective was (negatively) linked to happiness in particular (Drake et al. 2008). Positive relations can be recognized between past-positive and present-hedonistic time perspectives and happiness (Drake et al. 2008; Zimbardo and Boyd 1999). These research findings fit the increasingly accepted idea of the existence of an optimal balance in time perspective, which assumes a right mix of a positive view on the past, a hedonistic focus on the present and sufficient regard for future goals, compared to low scores on the past-negative and the present-fatalistic perspectives (Boniwell and Zimbardo 2004; Drake et al. 2008; Webster 2011). Surprisingly and worth mentioning, no significant relationship was found thus far between the future time perspective and happiness, while this perspective in particular is positively related to the general concept of well-being (Boniwell et al. 2010; Luszczynska et al. 2004). According to Boniwell and Zimbardo (2003) people who are too concerned with the future, don't have time for or notice pleasant events in the present.

The development of time perspective takes place under the influence of cultural and environmental factors and social processes such as socialisation, modelling, education etc. (Seginer 2003). Therefore it can be argued that as time passes by, changes in someone's mix of time perspectives will occur. An 80 year-old woman living her last years will in all probability contemplate the future in quite a different way than a young student, planning her career. The literature in this field of research supports this point of view. Bortner and Hultsch (1972) for instance reported a difference between age categories in appreciation of the past, present and future. Individuals in their fifties reported to have made progress in their lives and expected to continue to do so. Respondents in their sixties valued the past, present and future equally, while for the age group 70-80 the past was preferred over the present and the present over the future. In addition, Palgi and Shmotkin (2010) studied a group of 85 years and older and concluded that this group emphasised the past, confirming previous studies conducted in elderly (Mehlsen et al. 2003; Staudinger et al. 2003). However, other research reported a larger focus on the present than on the future, as for instance Fung and Carstensen (2003), who found that the elderly put less energy in future opportunities and events and rather concentrate on realistic goals in the present. Lennings (2000) argued that the focus of the elderly is directed mainly on the present, trying to incorporate parts of the past and the future into this present. 
Considering the reality of a shortening of future time while getting older, and with this, diminishing opportunities for change and/or improvement, as well as the discussed previous research findings concerning changes in time perspective with age, we assume that during someone's lifespan, the focus will shift from the future to the present and eventually to the past. If so, the question arises of what will happen to the perceived happiness? Will a diminished focus on the future have the same effect on the aforementioned old lady as it has on the young student, who still has most of her life in front of her? Or more generally, as formulated in our focal research question: How does age moderate the relationship between time perspective and happiness?

To structure our exploration of this research question, we conducted our study in three steps. First we looked into the association between time perspective and happiness, expecting happiness to be positively associated to time perspectives PP and PH (Drake et al. 2008; Zimbardo and Boyd 1999), and negatively associated to the time perspectives PN and PF (Crockett et al. 2009). No association between the future time perspective and happiness was expected. Secondly, we examined the association between age and time perspective to investigate the aforementioned age-related shift in time perspective. Or more explicitly, our second hypothesis assumes that with age a shift in time perspective will be recognized towards more emphasis on the present and the past and less on the future (Fung and Carstensen 2003; Lennings 2000; Palgi and Shmotkin 2010). In the third and final step of our study, we examined if and how age moderates the assumed association between time perspective and age. In line with earlier research and our second hypothesis, we assume that age indeed will make a difference and that, considering the shift towards the present and the past, the association between these time perspectives and happiness, as described in our first hypothesis, will become even stronger with age. We assume that age will strengthen the positive association between happiness and the time perspectives PP and $\mathrm{PH}$ as well as the negative associations with the time perspectives PN and PF.

\section{Methods}

\subsection{Measurement}

Happiness was measured by the Dutch version of the Subjective Happiness Scale (Lyubomirsky and Lepper 1999; Bartels and Boomsma 2009). This is a 4-item scale consisting of the items (1) "In general, I consider myself", using a 7-point Likert scale ranging from 1 (=not a very happy person) to 7 (=a very happy person); and (2) "Compared to most of my peers, I consider myself" using a 7-point Likert scale ranging from 1(=less happy) to 7(=more happy). With regard to items 3 and 4 respondents indicated to what extent $(1=$ not at all/ $7=$ a great deal $)$ the characterisation given by each item applied to them: (3) "Some people are generally very happy. They enjoy life regardless of what is going on, getting the most out of everything. To what extend does this characterisation describe you?" and (4) "Some people are generally not very happy. Although they are not depressed, they never seem as happy as they might be. To what extend does this characterisation describe you?" An average of the scores on these items was calculated.

Time perspective was measured by the Dutch version of the Zimbardo Time Perspective Inventory (ZTPI) (Zimbardo and Boyd 1999; Luyckx et al. 2010; van Beek et al. 2011). The ZTPI consists of 56 items measuring attitude, beliefs and behaviour regarding time. Respondents indicated per item the extent to which the item applied to them, ranging from 
$1=$ very uncharacteristic to $5=$ very characteristic. We give an example per time perspective: $(P P)$ "Familiar childhood sights, sounds, smells often bring back a flood of wonderful memories"; $(P N)$ "It's hard for me to forget unpleasant images of my youth"; $(P H)$ "I believe that getting together with one's friends to party is one of life's important pleasures"; $(P F)$ "Fate determines much in my life; $(F)$ I am able to resist temptations when I know that there is work to be done". An average of the scores on each time perspective subscale was calculated.

The homogeneity of both the ZTPI subscales PN, PP, PF, PH and F, and the Happiness scale, computed by Crohnbach's alpha $(n=525)$, measured above .65 (respectively $\alpha=.83 ; \alpha=.73 ; \alpha=.67 ; \alpha=.70 ; \alpha=.67 ;$ and $\alpha=.86, \mathrm{n}=525)$, indicating sufficient reliability of the scales (Evers et al. 2000; Nunnally and Bernstein 1994) for the purpose of this study.

During someone's life course his (her) family composition can change due to life events such as for example getting married, having kids, or the death of a partner. Literature shows that living alone versus living with others as well as having a life partner influences the individual's well-being (Hooghe and Vanhoutte 2011). Therefore we included household composition (living alone $=0 /$ living with others $=1$ ) and the presence of a life partner $($ no $=0 /$ yes $=1$ ) as dichotomous confounders. Sex was also included as a confounder $($ male $=0 /$ female $=1$ ), as sex differences in happiness were observed in recent research (Arrosa and Gandelman 2016).

\subsection{Sample}

The Facebook student page of the Open University of the Netherlands was used to invite people to participate in this research. The Open University of the Netherlands offers opportunities for flexible and part-time study, supported by an open access policy and an educational model of distance learning. Students of this university are adults with heterogeneity in variables as previous education, age, marital status, employment status, income etcetera. On the Facebook page a link was provided to the questionnaire of this study, which could be filled out and submitted online. In order to allow for sufficient respondents of older age $(60+)$, we also approached a local social network of elderly by email (once) with a request for participation. This email provided the link to the same questionnaire. Following the American Psychological Association Ethical principles of psychologists and code of conduct (American Psychological Association 2010), the questionnaire started out with a statement, explaining that participation was on a voluntary basis and that the participant could stop any time without giving any reason and without (adverse) effects. It also explained that by submitting the answers, participants consented to the careful and secure use of the data for this study, in compliance with their privacy rights.

The online questionnaire was filled out by 530 respondents. Five respondents were removed from the dataset based on: insufficient data $(>50 \%$ missing; $n=3)$, age was missing $(\mathrm{n}=1)$ and age was under $18(\mathrm{n}=1)$. The remaining missing values $(0.005 \%$ of the total dataset) were evenly distributed among the other 525 respondents and the two scales and were imputed by the mean score of all other respondents on that particular item. Our sample consisted of $32 \%$ male and $68 \%$ female respondents and age varied from 20 to 87 years $($ Mean $=49.15$ and $S D=14.01)$. The majority of the respondents $(82 \%)$ was sharing his/her household with others (partner and/or children). The remaining $18 \%$ lived alone of whom one third was in a relationship. 


\subsection{Analysis}

For the statistical analysis SPSS version 22 (IBM Corp. 2013) was used. To examine the association between the five time perspectives PP. PN, PF, PH and F (TPs) and happiness Pearson's correlations were computed between the ZTPI scores and happiness scores. Secondly a multiple regression analysis was conducted with happiness as dependent variable and the five time perspectives as independent variables. In this analysis age was included as a confounding variable in order to correct for a direct association between age and happiness. The other three confounders (sex, household composition and presence of a life partner) were included as well.

Next Pearson's correlations between age and ZTPI scores were computed and separate multiple regression analyses including the confounders, were conducted with respectively the time perspectives PP, PN, PH, PF and F as dependent variable and age as independent variable. In addition, the respondents were assigned to different age categories, in which we aimed for an optimum of comparable age intervals as well as sufficient respondents per age group. This resulted in the following age categories: $1=<30$ years, $n=52 ; 2=30-39$ years, $n=91$; $3=40-49$ years, $\quad n=114 ; \quad 4=50-59$ years, $n=142 ; \quad 5=60-69$ years, $n=87$; $6=>69$ years, $n=39$. The mean ZTPI scores in the six age categories were computed and compared using ANOVA. Post hoc analyses were corrected to control for type I error using the Bonferroni method $(p<.05)$, to allow for a clearer picture of profiles per age category and of the assumed shifts that might have taken place between these categories.

Finally to examine for the moderating role of age, multiple regression analyses, including $\mathrm{Z}$-scores of age and the five time perspectives and the interaction term (Z-score of age * Z-score of TP), were conducted (Aiken and West 1991; Cohen et al. 2003; Dawson 2014) per TP. The confounders sex, composition of household and presence of a life partner were again included in the analyses. If the interaction term proves to be significant in the regression analysis, we can assume that age has a moderating effect (Dawson 2014). For further exploration of this assumed moderation, a split regression analysis was conducted. Respondents were split up in two groups: one group of respondents under the average age of the total sample and one group of respondents above this average age. In both groups separate regression analyses were performed with respectively the time perspectives PP, PN, PH and PF as independent and happiness as dependent variable. Again the confounders were all included in the analyses.

Since no hypothesis was formulated regarding the importance of the variables in predicting the outcome in the analysis as described above, the forced entry method was used for conducting regression analyses (Enter as it is known in SPSS), in which all predictors are forced into the model simultaneously (Field 2009).

\section{Results}

Means, standard deviations and ranges of our core variables time perspective, happiness and age are presented in Table 1 . The scores appear not to be normally distributed. Both logarithm and square root transformation of the data did, however, not succeed in obtaining a normal distribution.

The results of the ANOVA analysis (Bonferroni corrected) showed that only those living alone and not having a life partner appeared to be a little less happy then respondents who shared their household with a partner or a partner and children $(F=3.11$, 
$\left.d f_{\text {between groups }}=5, d f_{\text {within groups }}=518, p<.01\right)$. An independent $t$ test did not result in a significant difference in happiness between men and women $(t(522)=1.34, p=.59)$.

The results of the correlation analysis showed significant negative correlations between $\mathrm{PN}$ and happiness $(r=-.54, p<.0001)$ and PF and happiness $(r=-.32, p<.0001)$ and significant positive correlations between PP and happiness $(r=.30, p<.0001)$ and $\mathrm{PH}$ and happiness $(r=.14, p=.002)$. No significant correlation between $\mathrm{F}$ and happiness was found. Results of the multiple regression analysis confirmed this pattern. The time perspectives of PH, PF, PP and PN were significantly associated with happiness (adjusted $\left.R^{2}=.38\right)$. Regression coefficients equalled respectively $\beta=.24,(p<.0001) ; \beta=-.17$ $(p<.0001) ; \beta=.11(p=.004)$; and $\beta=-.45(p<.0001)$. In addition, age was significantly positively associated with happiness $(\beta=.14, p<.0001)$ as well as household composition $(\beta=.11, p=.026)$.

The results of the correlation analysis in our second research step resulted in a rather weak but significant positive correlation between PF and age $(r=.17, p<.0001)$. No further significant correlations were found. Regression analysis confirmed this result, showing a significant positive association between $\mathrm{PF}$ and age $(\beta=.21, p<.0001)$, where sex $(\beta=.17, p<.0001)$ and the presence of a life partner $(\beta=-.13, p=.031)$, were also significantly associated with PF. The explained variance in PF by these variables was however quite small (adjusted $R^{2}=.08$ ). In none of the other TP regression models was age a significant factor. Further exploration of TP scores in different age categories revealed that the mean TP scores between the categories hardly differed. Significant differences were only observed between PF scores of the eldest group (70 years and older) and the other groups $\left(F=4,76, d f_{\text {between groups }}=5, d f_{\text {within groups }}=519, p<.0001\right)$, whereas the eldest group appeared to score significantly higher on PF. Furthermore the results indicated that the youngest group (younger than 30 years) scored significantly higher on $\mathrm{F}$ than age categories $30-39,40-49$ and 60-69. $\left(F=2.47, d f_{\text {between groups }}=5, d f_{\text {within groups }}=519, p=.032\right)$. However no other significant differences were found between the age categories in scores on F. In summary, with the exception of a weak association between age and PF and an increased focus on PF in the elder group, the assumed shifts in TP as people get older, were not found.

Finally the moderating role of age was explored, using moderated regression analysis per interaction term for each time perspective. The interaction term PN (Z-score) * age (Zscore) proved to be significant. No other significant interaction terms were found. Results are shown in Table 2.

When getting older, the negative association between PN and happiness weakens. Further examination of the data confirmed these results. In the younger age group (age $<50, n=255)$ the negative associations between PN and happiness $(\beta=-.61, p=.000)$ as well as between PF and happiness $(\beta-.40, p=.000)$ were stronger than in the older age group (age $>49, n=266$ ), where regression coefficients were shown of respectively $\beta=-.44(p=.000)$ and $\beta=-.27(p=.000)$. In addition, the younger group showed no significant association between $\mathrm{PH}$ and happiness, whereas in the older group a positive association between $\mathrm{PH}$ and happiness $(\beta=.20, p=.002)$ was found.

\section{Discussion}

The results of this study confirm earlier findings of the association between time perspective and happiness (Drake et al. 2008; Zimbardo and Boyd 1999). Our findings support the idea that a well-balanced time perspective - that is low scores on past-negative and 
Table 1 Means, standard deviations and ranges of the core variables

$N=525$

Table 2 Results of moderated regression analysis: age as moderator

$N=525$; Dependent variable: Happiness. Model: Enter

$* p<.01$. ** $p<.001$

\begin{tabular}{lrrrr}
\hline Variable & \multicolumn{1}{l}{ M } & \multicolumn{1}{c}{ SD } & Min & Max \\
\hline PN & 2.46 & .62 & 1.00 & 4.60 \\
PP & 3.47 & .51 & 1.22 & 4.78 \\
PF & 2.68 & .48 & 1.44 & 4.00 \\
PH & 3.21 & .39 & 2.07 & 4.60 \\
F & 3.35 & .37 & 2.08 & 4.31 \\
Happiness & 5.16 & 1.02 & 1.00 & 7.00 \\
Age (in years) & 49.15 & 14.01 & 20 & 87 \\
\hline
\end{tabular}

\begin{tabular}{lc}
\hline Predictor & $\beta$ \\
\hline PN (Z-score) &.$- .52 * *$ \\
age $(Z$-score) & .07 \\
PN (Z-score) * age (Z-score) & $.10^{*}$ \\
household & -.02 \\
life partner & .10 \\
sex & -.04 \\
Adj. $R^{2}=.31$ & \\
\hline
\end{tabular}

present-fatalistic time perspectives and high scores on past-positive and present-hedonistic perspectives - contributes to someone's happiness, as it does to well-being in more general (Drake et al. 2008; Boniwell and Zimbardo 2004; Webster 2011). Considering happiness as an aspect of well-being, these findings strengthen the idea that time perspective indeed plays a substantial role in people's well-being and can be an instrument for improvement.

The hypothesized shifts in time perspective with increasing age were not found, with the exception of a weak positive association between a present-fatalistic perspective and age. These results differ from earlier research (Fung and Carstensen 2003; Lennings 2000), that indeed demonstrates that elderly focus more on the past and/or present. Apart from the possibility that our research design may have been of influence, which will be discussed later in this section, it has been suggested that what someone experiences during his/her life can be determinative for his/her time perspective (which supports our idea that time perspective can shift over time). People can learn from experiences (Kolb 1984) and may develop new strategies to cope with life events (Folkman et al. 1987). It might be helpful to examine such factors in further research, especially if they are age-related. These factors, as well as the way people cope with them, in fact may moderate the association between age and time perspective. Negative experiences in the past may for instance either result in a past-negative perspective or indeed motivate someone to focus more on the present or future (forgetting, moving on). The path someone follows, may depend on personality (i.e. resilience), coping mechanism and former experiences (learning). The latter can be expected to increase in importance, when someone gets older (Ward et al. 2012).

In our study increasing age was associated with increasing self-reported happiness. Although this might be partly associated with the selection process of respondents, which we will refer to later in this section as well, lifespan research on well-being indicates that older adults experience the same or higher levels of positive affect and lower levels of negative affect than younger adults (Carstensen et al. 2000; Mroczek and Kolarz 1998). 
During ageing, life satisfaction seems to stabilize or even increase (Diener et al. 1999). An effective strategy elderly use to maintain happiness is selective optimization (Baltes and Baltes 1990), where they focus on areas that are important to them and compensate for other areas where loss is experienced.

Age was indeed found to be a moderator in the association between time perspective and happiness. In contradiction with our assumptions however, in our sample age weakens the negative association between the past-negative time perspective and happiness. Results of the final regression analyses performed separately in the two different age groups, support this moderation effect: the negative association between the past-negative time perspective was weaker in the older group than in the younger group. In addition, the older group showed a weaker association between a present-fatalistic time perspective and happiness than the younger group did.

Also a significant positive association between a present hedonistic time perspective and happiness was found in the older group, but not in the younger group. Although the latter is supportive of our assumption that the association between this time perspective and happiness will be stronger for the elderly, a moderation effect of age on this association was not found.

Our findings challenge us to reconsider the value of time perspective for different age categories. With regard to the weakening effect of age on the association between a pastnegative time perspective and happiness, it can be assumed that, even though the focus of the elderly may be on the past or present (i.e. Fung and Carstensen 2003; Palgi and Shmotkin 2010), from a certain age a negative past may be of less influence on someone's present happiness. This could be interpreted as applying the selective optimization strategy — which has mainly been studied regarding (physical and mental) abilities and skills (i.e. Bajor and Baltes 2003; Baltes and Cartsensen 2003) - to life events and the loss of loved ones. Instead of focusing on these losses or negative events in the past, people may refocus on more positive things in their past and their present. Recent research findings that show that 'acceptance of what cannot be changed' is positively related to well-being of the elderly (Broadbent et al. 2014), fit this interpretation. With regard to this acceptance, it can also be argued that a fatalistic perspective on the present can have a different meaning for older than for younger individuals. For the elderly, this time perspective may manifest itself less in a feeling of helplessness, but rather in some form of acceptance of life as it is and has been.

In addition, to some extent, passed time after negative experiences may have simply smoothened the effects or taken off the edge of these past events. Wohl and McGrath (2007) for example found that passed time can help people to cope with negative interpersonal experiences.

Although some critical notes can be made regarding our study (which will be addressed next in this section), our findings suggest that the optimal balance of time perspective (Boniwell and Zimbardo 2004; Drake et al. 2008; Webster 2011) is subject to change over time and may considerably differ for younger and older age categories.

\subsection{Practical Implications}

The results of this study support the idea that adjusting an individual's focus on the present and/or past can indeed help to increase someone's well-being and happiness (Boniwell and Zimbardo 2004). The finding that age moderates the association between time perspective and happiness, shed new light on this idea, arguing that the optimal balance of time perspective may differ for older individuals and the younger ones. With regard to younger 
age categories in our sample, the earlier mentioned optimal balance of time perspective (i.e. Webster 2011), can indeed be positively associated with happiness (except for the future time perspective). Referring to the aforementioned example of the effect that negative life experiences may have on time perspective (resulting in either a strong pastnegative perspective or in a motivation to move on), younger adults going through difficult experiences in their lives, can be counselled towards a more balanced time perspective to help them cope, move on and retain happiness (Webster 2011).

The elderly might rather be helped by finding some (positive) resignation in or acceptance of their life course (Broadbent et al. 2014). With regard to their focus on the present, it seems less necessary, in contrast to younger age categories, to readjust a fatalistic perspective. Such a perspective may actually help to achieve some peace of mind and can indeed coexist with a present-hedonistic perspective. We assume that a positive focus on the present-which can consist of both a fatalistic and a hedonistic perspectivecan contribute to the experience of happiness in older age groups. Combining interventions regarding time perspective with other strategies as applied in selective optimization may indeed optimize effects on well-being in this age group.

\subsection{Critical Notes and Future Research}

Several critical notes regarding our study can be made. These remarks do not only call for caution in drawing firm conclusions, but can also be helpful for further research. First of all this study had a cross-sectional design. Studying shifts in time perspective over time and accompanying changes in the association between time perspective and happiness (or any other aspect of well-being) is ideally conducted in a cohort-sequential design. In case a cross-sectional design is preferred, one should strive for a well-balanced sample in which the different age categories are sufficiently and equally represented. Using also more traditional ways of data collection will help to involve a more divers group of elderly. As mentioned before, the group elderly considered themselves as quite happy. Although earlier research results of well-being and aging corresponds with this finding (Diener et al. 1999; Ehrlich and Isaacowitz 2002), our online data collection method has excluded a probably still wide range of elderly that have not stepped into the digital world (yet), which may have resulted in less variance in our sample.

Additionally, to further disentangle the moderating role of age in the association between time perspective and happiness, the assessment of age-related factors or events such as graduating, first employment, getting married, having children or negative life events such as unemployment, divorce or the loss of a loved one will be fruitful.

Finally happiness and well-being are of great importance for any age group. However, taking into consideration the quickly expanding group of elderly in our society, facing an increase of physical inabilities and the loss of loved ones, research in this age category is additionally important. Time perspective appears to be associated with happiness, but acts in a different way for the elderly than for younger people. With this study an effort was made to explore this moderating role of age and its theoretical and practical consequences that can add to our understanding of the optimal balance in time perspective in different age categories.

Acknowledgments The authors wish to thank Jos Beckers, Marleen Donk, Olivia Moussault, Jacqueline Sleeven, Jeanette Klein Snakenburg, Jannie Terlouw and Ina Venema from the Open University of the Netherlands for their help with the data collection. 
Open Access This article is distributed under the terms of the Creative Commons Attribution 4.0 International License (http://creativecommons.org/licenses/by/4.0/), which permits unrestricted use, distribution, and reproduction in any medium, provided you give appropriate credit to the original author(s) and the source, provide a link to the Creative Commons license, and indicate if changes were made.

\section{References}

Aiken, L. S., \& West, S. G. (1991). Multiple regression: Testing and interpreting interactions. Newbury Park, London: Sage.

American Psychological Association (2010). Ethical principles of psychologists and code of conduct. http:// www.apa.org/ethics/code/index.aspx.

Arrosa, M. L., \& Gandelman, N. (2016). Happiness decomposition: Female optimism. Journal of Happiness Studies, 17(2), 731-756.

Bajor, J., \& Baltes, B. (2003). The relationship between selection optimization with compensation, conscientiousness, motivation, and performance. Journal of Vocational Behavior, 63, 347-367.

Baltes, P. B., \& Baltes, M. M. (1990). Psychological perspectives on successful aging: The model of selective optimization with compensation. In P. B. Baltes \& M. M. Baltes (Eds.), Successful aging: Perspectives from the behavioral sciences (pp. 1-34). Cambridge: Cambridge University Press.

Baltes, M. M., \& Cartsensen, L. (2003). The process of successful aging: Selection, optimization and compensation. In U. Staudinger \& U. Lindenberger (Eds.), Understanding human development: Dialogues with lifespan psychology (pp. 81-104). Dordrecht: Kluwer Academic Publishers.

Bartels, M., \& Boomsma, D. I. (2009). Born to be happy? The etiology of subjective well-being. Behavior Genetics, 39(6), 605-615.

Boniwell, I., Osin, E., Linley, P. A., \& Ivanchenko, V. (2010). A question of balance: Time perspective and well-being in British and Russian samples. The Journal of Positive Psychology, 5(1), 24-40.

Boniwell, I., \& Zimbardo, P. (2003). Time to find the right balance. The Psychologist, 16(3), $129-131$.

Boniwell, I., \& Zimbardo, P. (2004). Balancing time perspective in pursuit of optimal functioning. In P. A. Linley \& S. Joseph (Eds.), Positive psychology in practice (pp. 165-178). New Jersey: Wiley.

Bortner, W. B., \& Hultsch, D. F. (1972). Personal time perspective in adulthood. Developmental Psychology, 7(2), 98-103.

Broadbent, J., de Quadros-Wander, S., \& McGillivray, J. A. (2014). Perceived control's influence on wellbeing in residential care versus community dwelling older adults. Journal of Happiness Studies, 15(4), $845-855$.

Carstensen, L. L., Pasupathi, M., Mayr, U., \& Nesselroade, J. R. (2000). Emotional experience in everyday life across the adult life span. Journal of Personality and Social Psychology, 79(4), 644-655.

Cohen, J., Cohen, P., West, S. G., \& Aiken, L. S. (2003). Applied multiple regression/correlation analysis for the behavioral sciences (3rd ed.). Mahwah: Erlbaum.

Crockett, R. A., Weiman, J., Hankins, M., \& Martenau, Th. (2009). Time orientation and health related behavior. Psychology and Health, 24(3), 333-350.

Dawson, J. F. (2014). Moderation in management research: What, why, when and how. Journal of Business and Psychology, 29, 1-19.

Diener, E., Suh, E. M., Lucas, R. E., \& Smith, H. L. (1999). Subjective well-being: Three decades of progress. Psychological Bulletin, 125(2), 276-302.

Drake, L., Duncan, E., Sutherland, F., Abernethy, C., \& Henry, C. (2008). Time perspective and correlates of wellbeing. Time and Society, 17(1), 47-61.

Ehrlich, B. S., \& Isaacowitz, D. M. (2002). Does subjective well-being increase with age? Perspectives in Psychology, 5, 20-26.

Evers, A., van Vliet-Mulder, J., \& Groot, C. (2000). Documentatie van tests en testresearch in Nederland: Deel I en Deel II (met aanvullingen). Assen/Maastricht: Van Gorcum.

Field, A. (2009). Discovering statistics using SPSS. London: Sage.

Folkman, S., Lazarus, R. S., Pimley, S., \& Novacek, J. (1987). Age differences in stress and coping processes. Psychology and Aging, 2(2), 171-184.

Fung, H., \& Carstensen, L. L. (2003). Sending memorable messages to the old: Age differences in preferences and memory for advertisements. Journal of Personality and Social Psychology, 85, 163-178.

Hicks, J. A., Davis, W. E., Trent, J., \& King, L. A. (2012). Positive affect, meaning in life, and future time perspective: an application of socioemotional selectivity theory. Psychology and Aging, 27(1), $181-189$.

Hooghe, M., \& Vanhoutte, B. (2011). Subjective well-being and social capital in Belgian communities. The impact of community characteristics on subjective well-being indicators in Belgium. Social Indicators Research, 100(1), 17-36. 
IBM Corp. (2013). IBM SPSS statistics for windows, version 22.0. Armonk: IBM Corp.

Kolb, D. A. (1984). Experiential learning: Experience as the source of learning and development. Englewood Cliffs: Prentice Hall.

Lennings, C. J. (2000). Optimism, satisfaction and time perspective and time perspective in the elderly. International Journal of Aging and Human Development, 51, 167-181.

Luszczynska, A., Gibbons, F. X., Piko, B. F., \& Tekozel, M. (2004). Self-regulatory cognitions, social comparison, and perceived peers' behaviors as predictors of nutrition and physical activity: A comparison among adolescents in Hungary, Poland, Turkey, and USA. Psychology and Health, 19(5), 577-593.

Luyckx, K., Lens, W., Smits, I., \& Goossens, L. (2010). Time perspective and identity formation: Short-term longitudinal dynamics in college students. International Journal of Behavioral Development, 34(3), $238-247$.

Lyubomirsky, S., \& Lepper, H. S. (1999). A measure of subjective happiness: Preliminary reliability and construct validation. Social Indicators Research, 46(2), 137-155.

Mehlsen, M., Platz, M., \& Fromholt, P. (2003). Life satisfaction across the life course: evaluations of the most and least satisfying decades of the life. International Journal of Aging and Human Development, 57, 217-236.

Mroczek, D. K., \& Kolarz, C. M. (1998). The effect of age on positive and negative affect: A developmental perspective on happiness. Journal of Personality and Social Psychology, 75(5), 1333-1349.

Nunnally, J. C., \& Bernstein, I. H. (1994). Psychometric theory. New York: McGraw Hill.

Palgi, Y., \& Shmotkin, D. (2010). The predicament of time near the end of life: Time perspective trajectories of life satisfaction among the old-old. Aging and Mental Health, 14(5), 577-586.

Seginer, R. (2003). Adolescent future orientation: An integrated cultural and ecological perspective. In W. J. Lonner, D. L. Dinnel, \& S. A. Hayes (Eds.), Online readings in psychology and culture. Bellingham: Center for Cross Cultural Research.

Staudinger, U. M., Bluck, S., \& Herzberg, P. Y. (2003). Looking back and looking ahead: Adult age differences in consistency of diachronous ratings of subjective well-being. Psychology and Aging, 18, 13-24.

van Beek, W., Berghuis, H., Kerkhof, A., \& Beekman, A. (2011). Time perspective, personality and psychopathology: Zimbardo's time perspective inventory in psychiatry. Time Society, 20(3), 364-374.

Ward, L., Barnes, M., \& Gahagan, B. (2012). Well-being in old age: Findings from participatory research. Brighton, Hove and Portslade: University of Brighton and Age Concern.

Webster, J. D. (2011). A new measure of time perspective: Initial psychometric findings for the balanced time perspective scale (BTPS). Canadian Journal of Behavioural Science, 43(2), 111-118.

Wohl, M. J. A., \& McGrath, A. L. (2007). The perception of time heals all wounds: Temporal distance effects willingness to forgive following an interpersonal transgression. Personality and Social Psychology Bulletin, 33(7), 1023-1035.

Zimbardo, P. G., \& Boyd, J. N. (1999). Putting time in perspective: A valid, reliable individual differences metric. Journal of Personality and Social Psychology, 77(6), 1271-1288.

Zimbardo, P. G., Keough, K. A., \& Boyd, J. N. (1997). Present time perspective as a predictor of risky driving. Personality and Individual Differences, 23, 1007-1023. 